\title{
Dielectric relaxation and ionic conductivity studies of $\mathrm{Na}_{2} \mathrm{ZnP}_{2} \mathrm{O}_{7}$
}

\author{
S CHOUAIB*, A BEN RHAIEM and K GUIDARA \\ Laboratoire de L'Etat Solide, Faculté des Sciences, de Sfax-BP 1171-3000 Sfax, Tunisia
}

MS received 10 December 2009; revised 28 January 2010

\begin{abstract}
The $\mathrm{Na}_{2} \mathrm{ZnP}_{2} \mathrm{O}_{7}$ compound was obtained by the conventional solid-state reaction. The sample was characterized by $\mathrm{X}$-ray powder diffraction, infrared analysis and electrical impedance spectroscopy. The impedance plots show semicircle arcs at different temperatures and an electrical equivalent circuit has been proposed to explain the impedance results. The circuits consist of the parallel combination of bulk resistance $R_{\mathrm{p}}$ and constant phase elements CPE. Dielectric data were analyzed using complex electrical modulus $M^{*}$ for the sample at various temperatures. The frequency dependence of the conductivity is interpreted in terms of Jonscher's law. The conductivity $\sigma_{\text {d.c. }}$ follows the Arrhenius relation. The near value of activation energies obtained from the analysis of $M^{\prime \prime}$ and conductivity data confirms that the transport is through ion hopping mechanism, dominated by the motion of the $\mathrm{Na}^{+}$ions in the structure of the investigated materials.
\end{abstract}

Keywords. Equivalent circuit; electrical modulus; a.c. conductivity; hopping mechanism.

\section{Introduction}

Double phosphates of $\mathrm{A}_{2} \mathrm{BP}_{2} \mathrm{O}_{7}$ formulation containing simultaneously an alkaline ion $\left(\mathrm{A}^{+}\right)$and a divalent cation $\left(\mathrm{B}^{2+}\right)$ form a large family of materials (El Maadi et al 1995; Erragh et al 1995; Erragh et al 1998; Sanz et al 1999; Belharouak et al 2000; Dridi et al 2000; Dridi et al 2001). The structure of these phosphates which have been the object of a single crystal structure investigation are diverse, and it is difficult to classify these materials as a function of classical fundamental criteria such us cation size, coordination number or chemical bonding. Selecting the $\mathrm{Na}^{+}$and $\mathrm{Zn}^{2+}$ cations as $\mathrm{A}^{+}$and $\mathrm{B}^{2+}$ ions, respectively, are interested, in the present work.

The crystal structure of $\mathrm{Na}_{2} \mathrm{ZnP}_{2} \mathrm{O}_{7}$ has been determined by X-ray diffraction using single crystals. This compound crystallized in the tetragonal system with the space group $P 4_{2} / n$ and unit cell parameters: $a=b=$ $21.771 \AA$ and $c=10.285 \AA$. The structure is made up of $\left[\mathrm{ZnP}_{2} \mathrm{O}_{7}\right]$ layers consisting of corners sharing $\left[\mathrm{P}_{2} \mathrm{O}_{7}\right]$ groups and $\left[\mathrm{ZnO}_{4}\right]$ tetrahedral, and the sodium atoms are located between the layers in 7- or 8-fold coordinated sites (figure 1) (Belharouak et al 2000).

In the present work, we propose to investigate the electrical and dielectrical properties of the $\mathrm{Na}_{2} \mathrm{ZnP}_{2} \mathrm{O}_{7}$ compound as a function of frequency and temperature.

\section{Experimental}

The $\mathrm{Na}_{2} \mathrm{ZnP}_{2} \mathrm{O}_{7}$ compound was synthesized by the classic ceramic method. Stoichiometric quantities of $\mathrm{Na}_{2} \mathrm{CO}_{3}$,

*Author for correspondence
$\mathrm{ZnO}$ and $\left(\mathrm{NH}_{4}\right)_{2} \mathrm{HPO}_{4}$ were well ground, mixed, and progressively heated first to $523 \mathrm{~K}$ to expel $\mathrm{NH}_{3}$ and $\mathrm{H}_{2} \mathrm{O}$ and then to $623 \mathrm{~K}$.

$\mathrm{X}$-ray powder diffraction pattern was recorded using a Philips PW 1710 diffractometer operating with copper radiation $K_{\alpha}=1.5418 \AA$. Units cells parameters of the synthesized compound have been refined by the least square method from the powder data.

The infrared absorption spectrum of crystalline powders in $\mathrm{KBr}$ was recorded on a FT-IR 470 Shymadzu spectrophotometer in $400-1300 \mathrm{~cm}^{-1}$ range.

The electrical measurements were performed using a two-electrode configuration. The polycrystalline $\mathrm{Na}_{2} \mathrm{ZnP}_{2} \mathrm{O}_{7}$ sample was pressed into pellets of $8 \mathrm{~mm}$ diameter and $0.8 \mathrm{~mm}$ thickness using $3 \mathrm{t} / \mathrm{cm}^{2}$ uniaxial pressure. Electrical impedances were measured in the frequency ranging from $200 \mathrm{~Hz}$ to $5 \mathrm{MHz}$ with the TEGAM 3550 ALF automatic bridge monitored by a microcomputer between 600 and $690 \mathrm{~K}$.

\section{X-ray powder analysis}

The X-ray powder diffractogram (figure 2) reveals that the synthesized compound crystallizes in the tetragonal system with the space group $P 4_{2} / n$ and the refined unit cell parameters are: $a=b=21.775 \AA$ and $c=10.287 \AA$, which are in good agreement with the literature values (Dridi et al 2001).

\section{Infrared absorption spectroscopy}

The infrared spectrum of the $\mathrm{Na}_{2} \mathrm{ZnP}_{2} \mathrm{O}_{7}$ compound at room temperature is shown in figure 3. A detailed 
assignment of all bands is difficult but we can attribute some of them by comparison with similar compounds (Santha et al 1993; Mahadevan Pillai et al 1999; Kuhlmann et al 2001). The principal bands are assigned to the internal modes of $\left(\mathrm{P}_{2} \mathrm{O}_{7}\right)$ group: two bands are observed at 1176 and $1086 \mathrm{~cm}^{-1}$, which were assigned respectively to the $v_{\text {as }}\left(\mathrm{PO}_{3}\right)$ and $v_{\mathrm{s}}\left(\mathrm{PO}_{3}\right)$ modes. The two strong bonds observed at 916 and $722 \mathrm{~cm}^{-1}$ were assigned to asymmetric $v_{\mathrm{as}}$ (POP) and symmetric $v_{\mathrm{s}}$ (POP) stretching vibrations of bridging $(\mathrm{P}-\mathrm{O}-\mathrm{P})$ modes. A smaller one, assigned to the symmetrical (POP) deformation mode $\delta_{\mathrm{s}}$ (POP) arises near $530 \mathrm{~cm}^{-1}$. Two bands are observed at 626 and $550 \mathrm{~cm}^{-1}$ were assigned respectively to the $\delta_{\text {as }}$ $\left(\mathrm{PO}_{3}\right)$ and $\delta_{\mathrm{s}}\left(\mathrm{PO}_{3}\right)$ deformation modes. Another band, assigned to the $\left(\mathrm{PO}_{3}\right)$ rocking $\rho_{\mathrm{r}}\left(\mathrm{PO}_{3}\right)$, was observed near $498 \mathrm{~cm}^{-1}$.

Note that one of the most interesting aspects of this study is the ability to obtain direct information about the configuration of the $\mathrm{P}-\mathrm{O}-\mathrm{P}$ bridges. The symmetric $\mathrm{POP}$ stretching mode $\delta_{\mathrm{s}}$ (POP) confirms the presence of the diphosphate group in the compound.

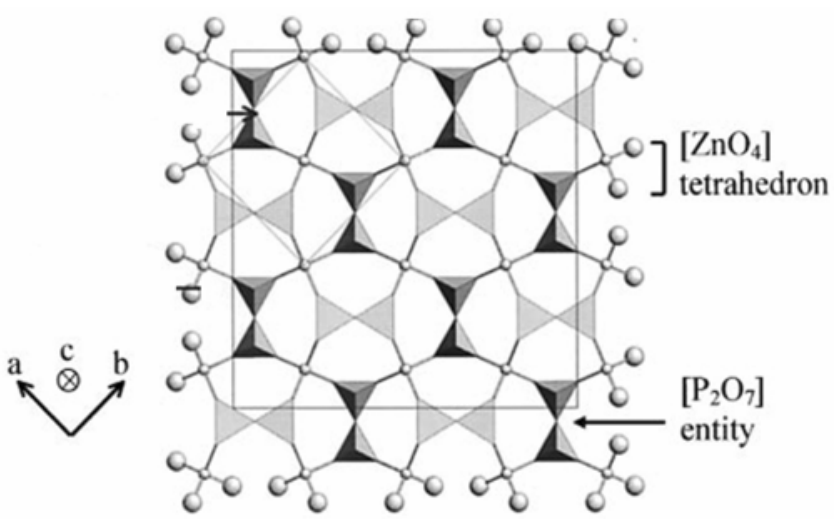

Figure 1. Projection of the $\mathrm{Na}_{2} \mathrm{ZnP}_{2} \mathrm{O}_{7}$ structure on the $(\mathrm{a}, \mathrm{b})$ plan.

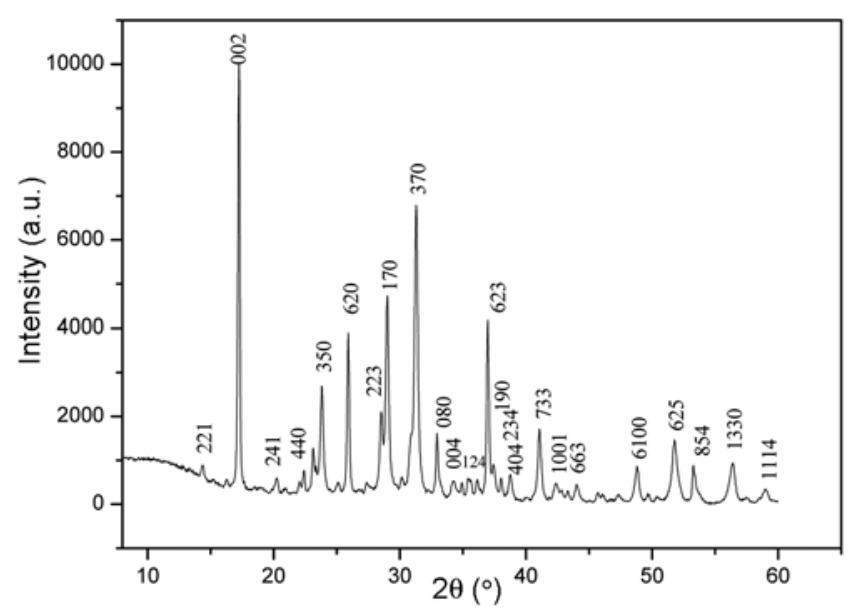

Figure 2. X-ray diffractogram of $\mathrm{Na}_{2} \mathrm{ZnP}_{2} \mathrm{O}_{7}$ compound.

\section{Dielectric study}

\subsection{Impedance spectrum analysis}

Figure 4 shows the complex impedance spectra of $\mathrm{Na}_{2} \mathrm{ZnP}_{2} \mathrm{O}_{7}$ for some representative temperatures. The

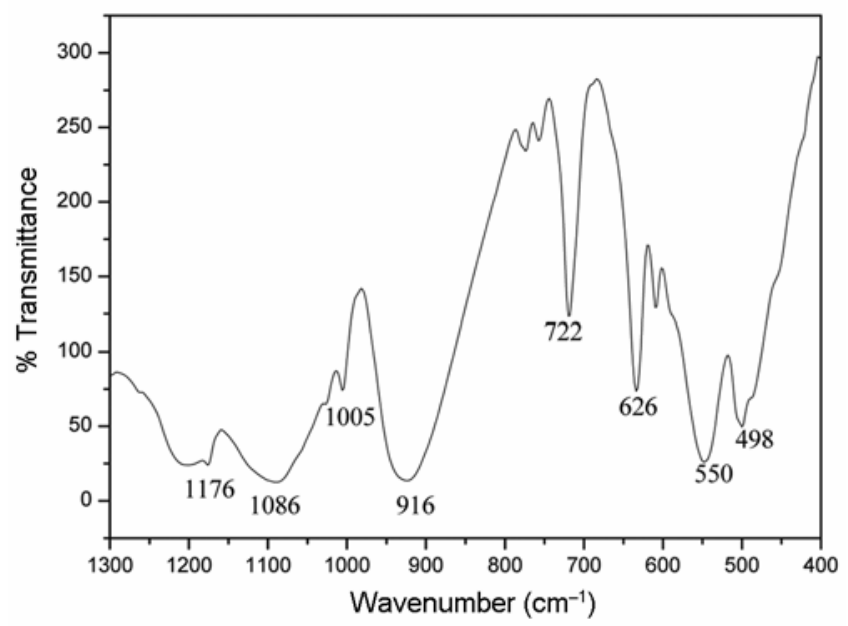

Figure 3. Infrared spectra of the $\mathrm{Na}_{2} \mathrm{ZnP}_{2} \mathrm{O}_{7}$ compound.
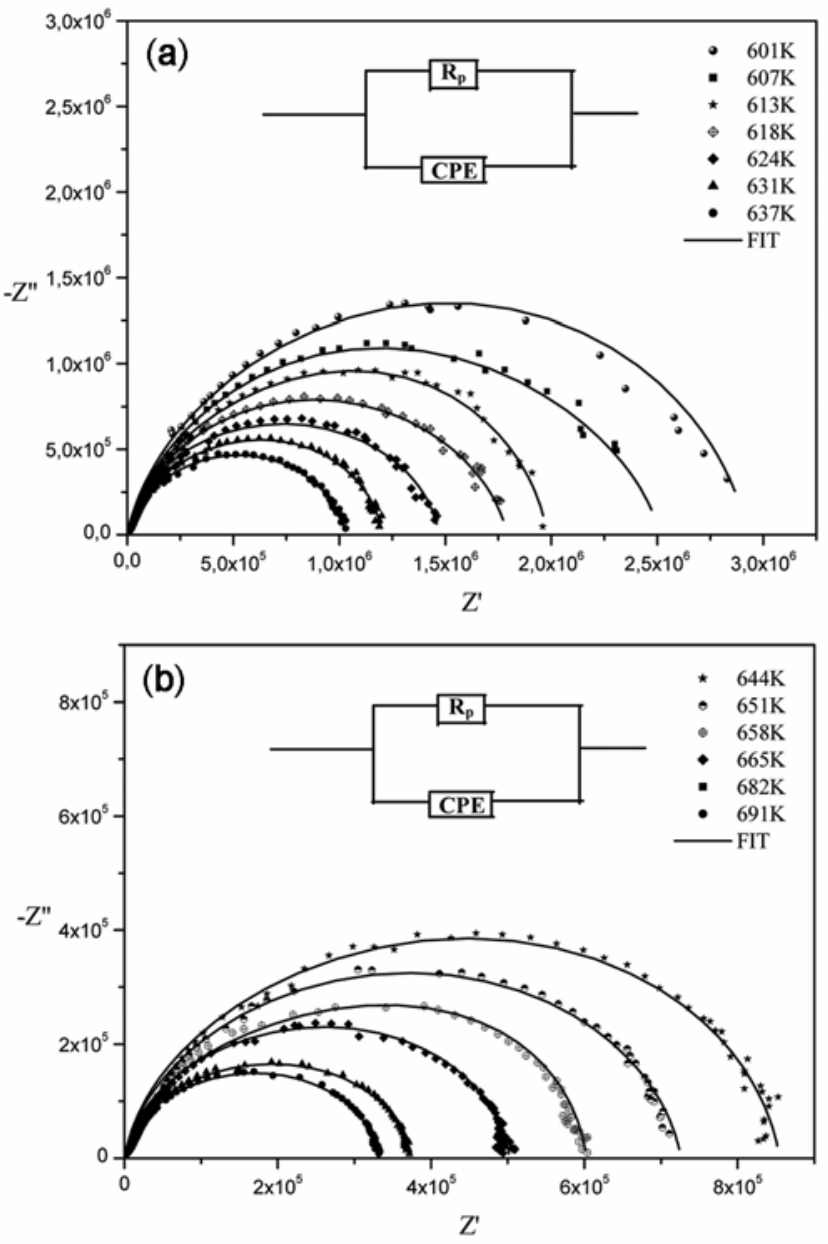

Figure 4. Experimental and simulated semicircles plots at different temperatures. 
spectra are characterized by the appearance of semicircle arcs whose pattern changes, but not its shape, when the temperature is increased. Such pattern tells us about the electrical process occurring within the sample and their correlation with the sample microstructure when modeled in terms of an electrical equivalent circuit (Ben Rhaiem et al 2005; Nadeem et al 2005; Parathan et al 2005). The equivalent circuit configuration for the impedance plan plot is the resistance $R_{\mathrm{p}}$ (bulk resistance) and in the terms of complex elements: constant phase elements (capacity of the fractal interface $\mathrm{CPE}$ ). The impedance of $\mathrm{CPE}$ is

$$
Z_{\mathrm{CPE}}=1 / Q(j \omega)^{\alpha},
$$

where $Q$ indicates the value of capacitance of the $\mathrm{CPE}$ element and $\alpha$ is the fractal exponent. Further, (1) shows that as $\alpha \rightarrow 1, Z_{\mathrm{CPE}} \rightarrow 1 / j Q \omega$, involving a pure capacitance, and as $\alpha \rightarrow 0, Z_{\mathrm{CPE}} \rightarrow 1 / Q$, a pure conductance.

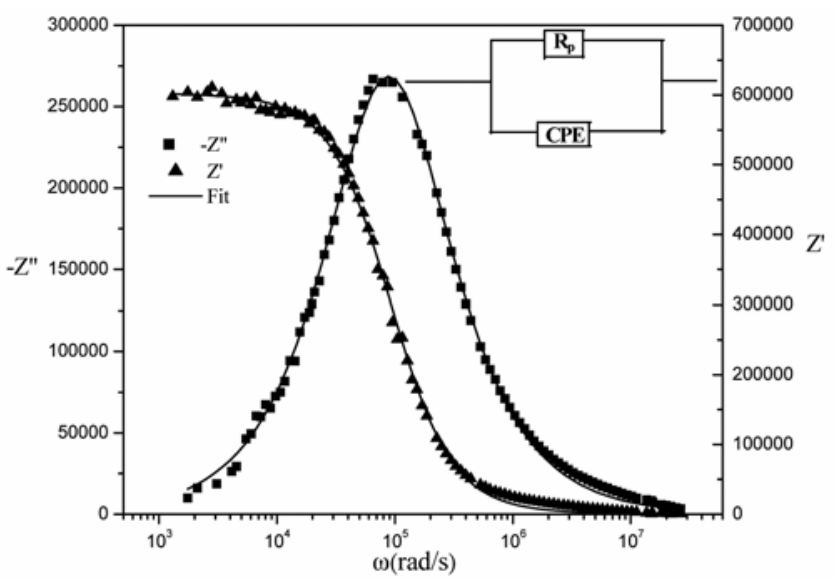

Figure 5. Variation of $Z^{\prime}$ and $-Z^{\prime \prime}$ with angular frequency at $685 \mathrm{~K}$

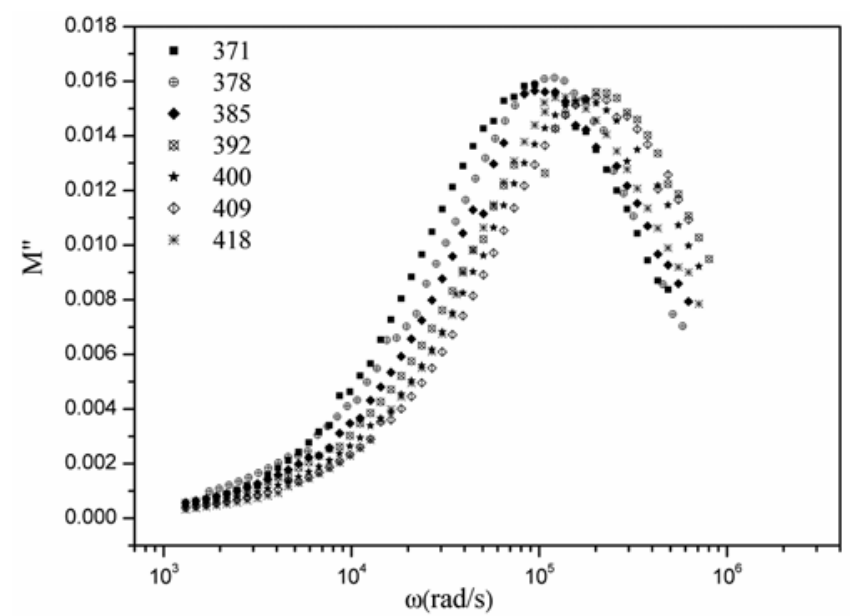

Figure 6. Angular frequency dependence of the imaginary part of electric modulus at several temperatures.
The real and imaginary components of the whole impedance of this circuit were calculated according to the following expressions:

$$
\begin{aligned}
& Z^{\prime}=\frac{R_{\mathrm{p}}^{2} Q \omega^{\alpha} \cos (\alpha \pi / 2)+R_{\mathrm{p}}}{\left(1+R_{\mathrm{p}} Q \omega^{\alpha} \cos (\alpha \pi / 2)\right)^{2}+\left(R_{\mathrm{p}} Q \omega^{\alpha} \sin (\alpha \pi / 2)\right)^{2}}, \\
& -Z^{\prime \prime}=\frac{R_{\mathrm{p}}^{2} Q \omega^{\alpha} \sin (\alpha \pi / 2)}{\left(1+R_{\mathrm{p}} Q \omega^{\alpha} \cos (\alpha \pi / 2)\right)^{2}+\left(R_{\mathrm{p}} Q \omega^{\alpha} \sin (\alpha \pi / 2)\right)^{2}},
\end{aligned}
$$

$Z^{\prime},-Z^{\prime \prime}$ data measured at $685 \mathrm{~K}$ and their fits according to the above equations versus frequency are represented in figure 5 . The good conformity of calculated lines with the experimental measurement indicates that the suggested

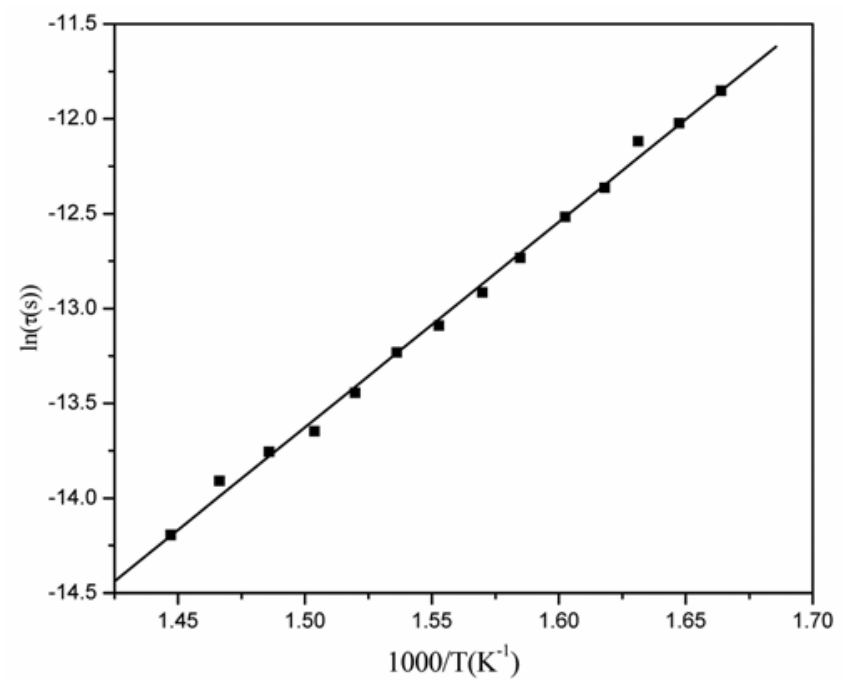

Figure 7. Temperature dependence of relaxation time $\tau(s)$.

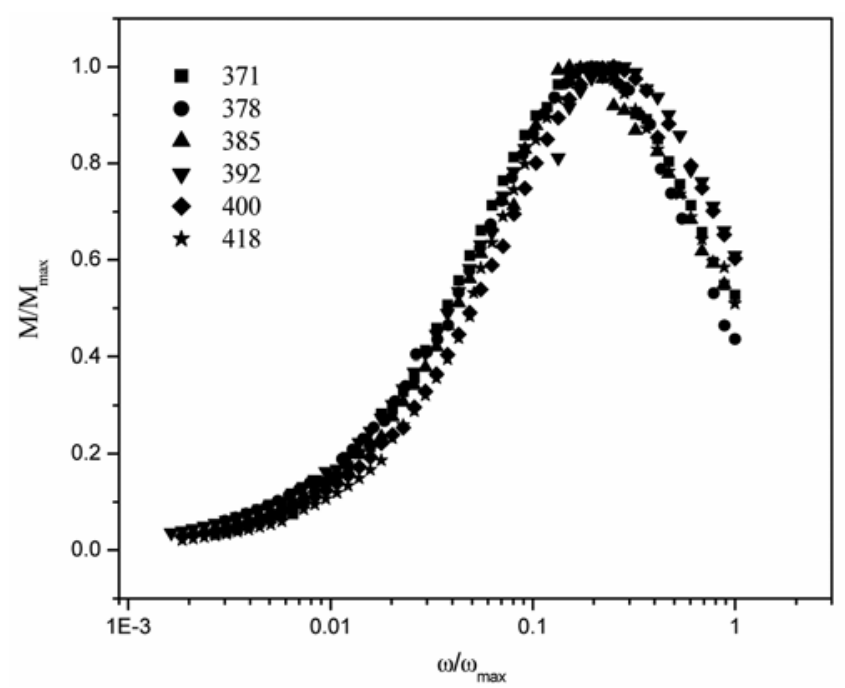

Figure 8. $M^{\prime \prime} / M^{\prime \prime}{ }_{\max }$ versus $\left(\omega / \omega_{\max }\right)$ at various temperatures. 
Table 1. Temperature dependence of $\alpha, Q$ and $R_{\mathrm{p}}$.

\begin{tabular}{lrrrrrrrrr}
\hline$T(\mathrm{~K})$ & 601 & 613 & 618 & 631 & 651 & 665 & 673 & 682 & 691 \\
\hline$\alpha$ & $0 \cdot 90$ & 0.93 & 0.91 & 0.92 & 0.92 & 0.93 & 0.92 & $0 \cdot 93$ & $0 \cdot 93$ \\
$Q(\mathrm{pF})$ & $45 \cdot 14$ & $35 \cdot 62$ & $44 \cdot 33$ & 37.85 & $42 \cdot 74$ & $39 \cdot 46$ & $39 \cdot 34$ & $39 \cdot 34$ & $40 \cdot 01$ \\
$R_{\mathrm{p}}(\Omega)$ & 2923843 & 1979207 & 1791261 & 1204432 & 726134 & 502556 & 431817 & 372073 & 331796 \\
\hline
\end{tabular}
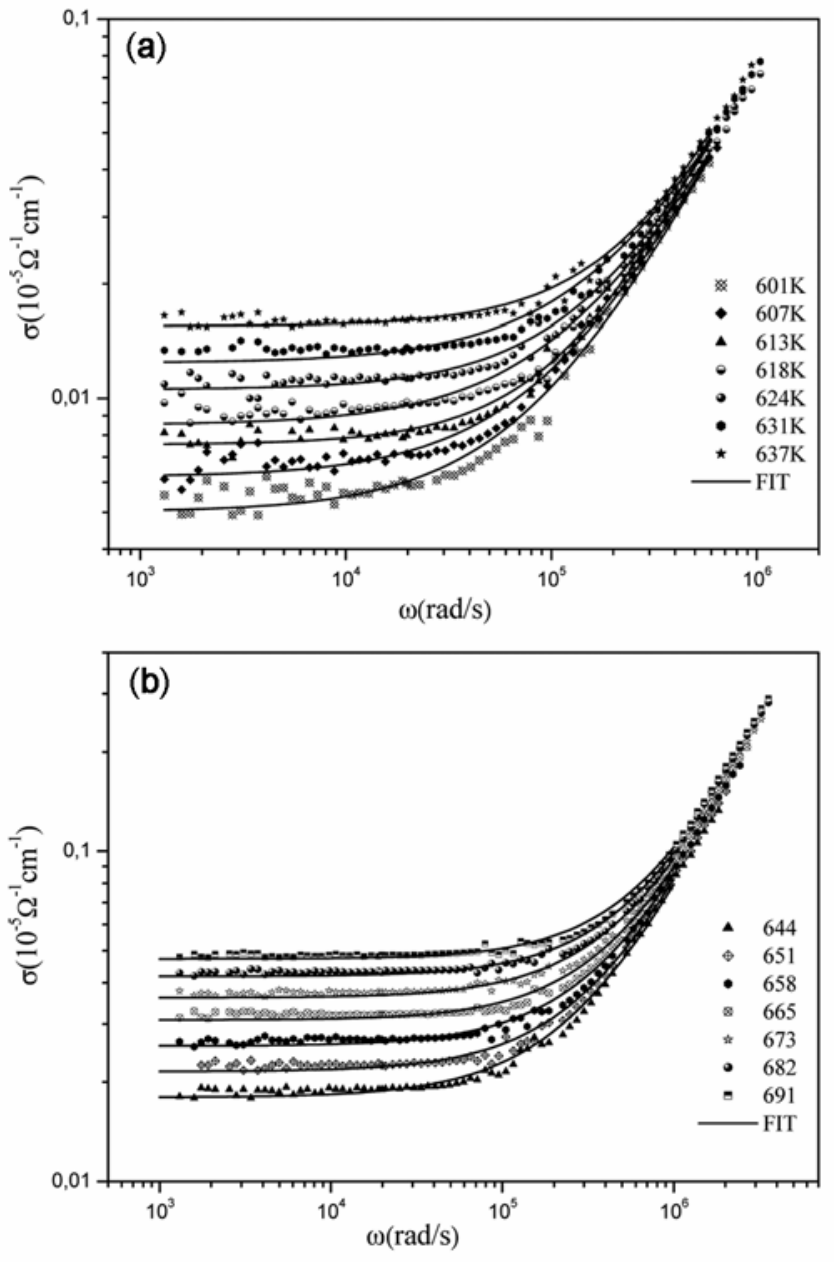

Figure 9. Angular frequency dependence of the a.c. conductivity at various temperatures.

equivalent circuit describes the crystal-electrolyte interface reasonably well.

Fitted values of $R_{\mathrm{p}}, Q$ and $\alpha$ parameters for different temperature are listed in table 1 . It is obvious that all the capacitance values $(Q)$ are in the range of $\mathrm{pF}$. This implies that the single semicircular response is from grain interiors, which is expected from the sample where no grain boundaries are involved. The values of $\alpha$ vary in the range $0 \cdot 9-1$ confirming the weakness interaction between localized sites.

\subsection{Modulus studies}

The modulus formalism is particularly suitable to extract phenomena such as electrode polarisation (Hodgeet et al
1976; Ganguli et al 1999; Lenfredi et al 2002) and conductivity relaxation times (Chen et al 1993; Reau et al 1997; Ghosh et al 2002; Lenfredi et al 2002). The complex electric modulus can be represented by the following equation

$$
M^{*}=\frac{1}{\varepsilon^{*}}=j \omega C_{0} Z^{*},
$$

where $C_{0}$ is the vacuum capacitance of the cell.

Figure 6 shows the variation of imaginary part of electric modulus as a function angular frequency at different temperatures. In the $M^{\prime \prime}$ plot, the peaks are broader and asymmetric on both sides of the maxima then predicted by ideal Debye behaviour. The frequency range where the peak occurs is indicative of the transition from long range to short range mobility. As temperature increases, the modulus peak maxima $\left(\omega_{\mathrm{m}}\right)$ move toward higher frequency, where $\omega_{\mathrm{m}}$ is the most probable relaxation rate, and is related to the most probable ion relaxation time, $\tau$, by the relation of $\omega_{\mathrm{m}} \tau=1$. The obtained temperature dependence of the relaxation time is plotted in figure 7 . It shows that the relaxation time appears thermally activated and can be described by Arrhenius law $\tau=\tau_{0}$ $\exp \left(E_{\mathrm{m}} / k_{\mathrm{B}} T\right)$, where $\tau_{0}$ is the pre-exponential factor $\left(\tau_{0}=2.43 \times 10^{-4} \mathrm{~s}\right), \quad E_{\mathrm{m}}$ is the activation energy from modulus $\left(E_{\mathrm{m}}=0.96 \mathrm{eV}\right)$ and $k_{\mathrm{B}}$ is Boltzmann's constant.

Figure 8 shows the normalized plot of $M^{\prime \prime} / M_{\max }^{\prime \prime}$ versus $\left(\omega / \omega_{\max }\right)$ at various temperatures. The normalised plot shows that all the curves for different temperature overlap a single master curve. This suggests that all possible relaxation mechanisms occurring at different frequencies exhibit the same thermal energy and the dynamical processes are temperature-independent. The modulus plot can be characterized by full width at half height or in terms of a nonexponential decay function (Sural and Gosh 2000; Gómez et al 2001; Anantha and Hariharan 2005; Padmasree et al 2006)

$$
\varphi(t)=\exp (-t / \tau)^{\beta}(0<\beta<1)
$$

where $\tau$ is the characteristic relaxation time and $\beta$ is the well known Kohlrausch parameter, which decreases with an increase in the relaxation time distribution. The $\beta$ value can be determinated by knowing the full width at half height $(\mathrm{FWHH})$ of the $M^{\prime \prime} / M_{\max }^{\prime \prime}$ plot $(\beta=1 \cdot 14 /$ $\mathrm{FWHH}=0.79)$.

\subsection{Electrical conductivity analysis}

The angular frequency dependence of a.c. conductivity at various temperatures for the sample is shown in figure 9. 
Table 2. $E_{\mathrm{C}}, \beta$ and $\sigma_{\text {d.c. }}$ parameters.

\begin{tabular}{lccc}
\hline & $\mathrm{Na}_{2} \mathrm{ZnP}_{2} \mathrm{O}_{7}$ & $\mathrm{AgNaZnP}_{2} \mathrm{O}_{7}[28]$ & $\mathrm{Ag}_{2} \mathrm{ZnP}_{2} \mathrm{O}_{7}[29]$ \\
\hline$E_{\mathrm{C}}(\mathrm{eV})$ & 0.94 & 0.79 & 0.72 \\
$\beta$ & 0.79 & 0.74 & 0.65 \\
$\sigma_{\text {d.c. }}\left(\Omega^{-1} \mathrm{~cm}^{-1}\right)$ & $\sigma_{600 \mathrm{~K}}=4.98 \times 10^{-8}$ & $\sigma_{550 \mathrm{~K}}=1.39 \times 10^{-7}$ & $\sigma_{550 \mathrm{~K}}=3.31 \times 10^{-5}$ \\
\hline
\end{tabular}

The data shows a frequency-independent conductivity for low frequencies and followed by an increase in conductivity for high frequency, quite similar to the vast majority of solids. The phenomena of the conductivity dispersion in solids are generally analyzed using Jonscher's power law:

$$
\sigma_{\mathrm{ac}}(\omega)=\sigma_{\text {d.c. }}+A \omega^{n},
$$

where $\sigma_{\text {d.c. }}$ is the direct current conductivity of the sample, $A$ is a constant for a particular temperature and $n$ is the power exponent.

The exponent $n$ represents the degree of interaction between mobile ions and the environments surrounding them. The transport mechanism is explained by the thermally activated hopping process between two sites separated by an energy barrier. The above equation has been used to fit the a.c. conductivity data. In the fitting procedure, $A$ and $n$ values have been varied simultaneously to get the best fits.

A plot of $-\ln (A)$ against $n$ (figure 10) indicates a linear temperature-independent and structure-insensitive correlation between the values of these two parameters. Such behaviour was observed in different types of materials and varied transport mechanism (Jonscher 1977; Louati et al 2005; Papathanassiou 2005).

D.C. conductivity data are plotted in Arrhenius format as $\ln \left(T \sigma_{\mathrm{dc}}\right)$ vs $1000 / T$ (figure 11) and show Arrheniustype behaviour described by

$$
T \sigma_{\text {d.c. }}=B \exp \left(-E_{\mathrm{c}} / k T\right),
$$

where $B\left(B=1.12610^{6} \Omega^{-1} \mathrm{~cm}^{-1} \mathrm{~K}\right)$ is the pre-exponential factor. The activation energy for conduction $\left(E_{\mathrm{C}}=0.94 \mathrm{eV}\right)$ is almost the same as that of the activation energy for the relaxation process $\left(E_{\mathrm{m}}=0.93 \mathrm{eV}\right)$. The near value of activation energies obtained from the analyses of $M^{\prime \prime}$ and conductivity data confirms that the transport is through ion hopping mechanism in the investigated material.

\section{Discussion}

In an earlier report we have studied the a.c. conductivity and dielectric behaviour of $\mathrm{Zn}_{2} \mathrm{P}_{2} \mathrm{O}_{7}$ compound as a function of temperature and frequency. The correlation between the $\mathrm{CBH}$ model and the crystallographic results permit us to deduce that the conduction is probably due to the motion of $\mathrm{Zn}^{2+}$ in the cationic layers and/or a long c-direction. This compound showed a very low ionic conductivity, when the $\sigma_{\text {d.c. }}=2 \times 10^{-7} \Omega^{-1} \mathrm{~cm}^{-1}$ at $730 \mathrm{~K}$ (Jarboui et al 2010).

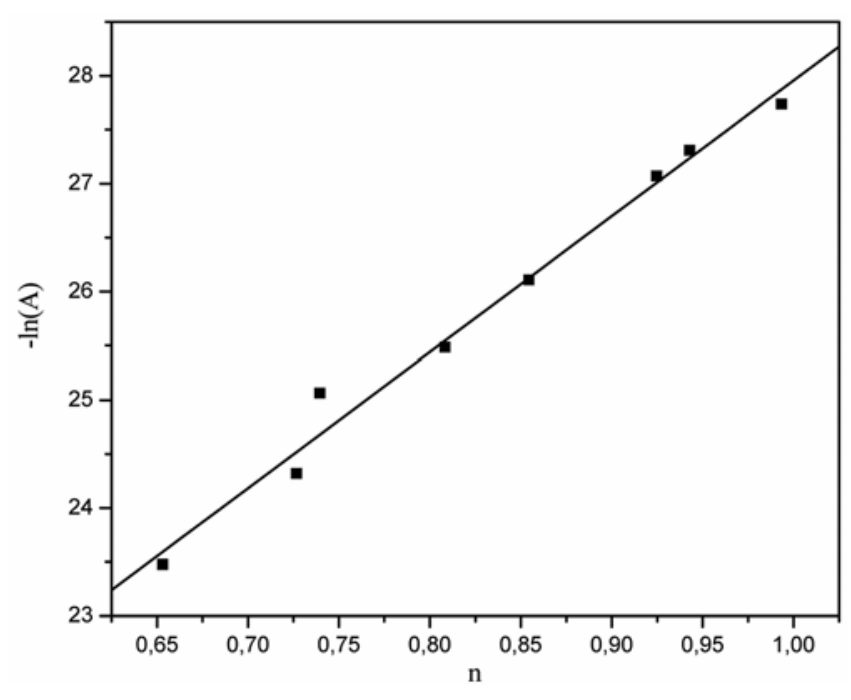

Figure 10. Plot of $-\ln (A)$ vs $n$.

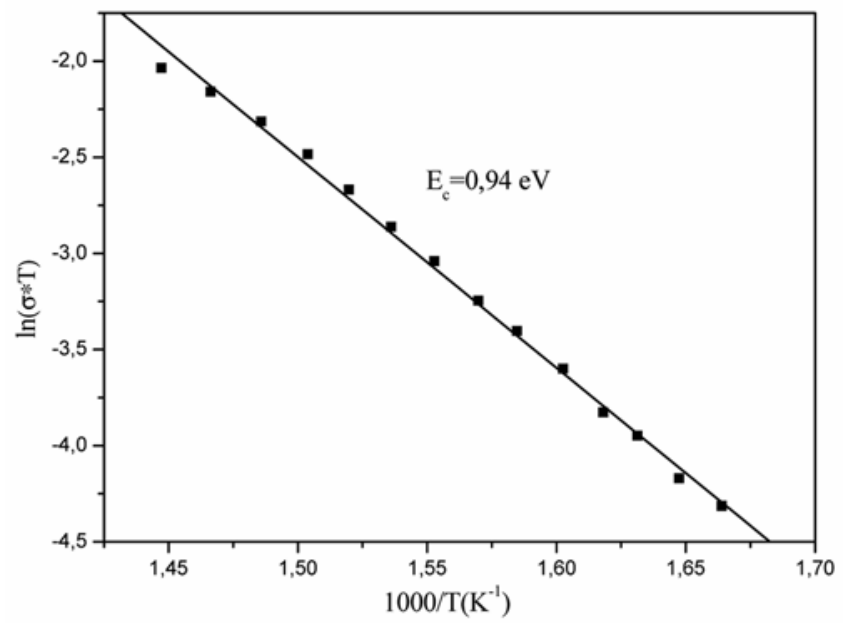

Figure 11. Plot of d.c. conductivity $\sigma_{\text {d.c. }}$ vs $1000 / T$.

Furthermore, we successfully introduced a monovalent cation into the $\mathrm{Zn}_{2} \mathrm{P}_{2} \mathrm{O}_{7}$ compound and we have synthesized the $\mathrm{A}_{2} \mathrm{ZnP}_{2} \mathrm{O}_{7}(A=\mathrm{Ag}$ and/or Na) compounds. The ionic conductivity of $\mathrm{Ag}_{2} \mathrm{ZnP}_{2} \mathrm{O}_{7}, \mathrm{AgNaZnP}_{2} \mathrm{O}_{7}$ and $\mathrm{Na}_{2} \mathrm{ZnP}_{2} \mathrm{O}_{7}$ compounds are characterized by the hopping of the $\mathrm{Na}^{+}$and/or $\mathrm{Ag}^{+}$ions (Ben Rhaiem et al 2009a, b).

The low frequency limit $\sigma_{\text {d.c. }}$ of the bulk $\sigma_{\text {a.c. }}$ conductivity determined by impedance spectroscopy is governed mainly by the hoping rate of free charge carriers and the charge carrier concentration $N(T)$ 


$$
\sigma_{\text {d.c. }}=e^{2} N(T) \gamma a_{\mathrm{h}}^{2}\left(v_{0} / \mathrm{kT}\right) \exp \left(S_{\mu} / k\right) \exp \left(-E_{\mu} / k T\right),
$$

where $a_{\mathrm{h}}$ is the hopping distance; $\gamma$ is a geometrical factor equal to $1 / 6$ for isotropic media; $v_{0}$ is an attempt frequency to overcome the potential barrier; $S_{\mu}$ is the migration entropy; $E_{\mu}$ is the migration energy; the other parameters having their conventional meaning (Almond et al 1987; Uvarovet et al 1994).

Identifying $E_{\mu}$ to $E_{\mathrm{c}}$ the pre-exponential factor $B$ is

$$
B=\left(e^{2} a_{\mathrm{h}}^{2} v_{0} / 6 k\right) N(T) \exp \left(S_{\mu} / k\right) .
$$

The electrical properties of $\mathrm{Na}_{2} \mathrm{ZnP}_{2} \mathrm{O}_{7}, \mathrm{AgNaZnP}_{2} \mathrm{O}_{7}$ and $\mathrm{Ag}_{2} \mathrm{ZnP}_{2} \mathrm{O}_{7}$ are compared in table 2. The better properties obtained for $\mathrm{Ag}_{2} \mathrm{ZnP}_{2} \mathrm{O}_{7}$ can be attributed to

- The number of charge carriers $N(T)$ participating in conductivity phenomena in $\mathrm{Ag}_{2} \mathrm{ZnP}_{2} \mathrm{O}_{7}$ is very superior than that observed in the studied compound. This is due to the fact that the polarizability of $\mathrm{Ag}^{+}$ions ( $d^{10}$ configuration) is higher than in the case of $\mathrm{Na}^{+}$. $\mathrm{Ag}^{+}$passes more easily through the bottlenecks and consequently more mobile than the $\mathrm{Na}^{+}$ions (Belharouak et al 2000).

- A larger migration entropy term resulting from a more important disorder in Ag-metal than for AgNa-metal and Na-metal. The increase of entropy term is confirmed by the decrease of parameter (table 2) (Dridi et al 2001).

\section{Conclusions}

The a.c. conductivity and dielectric behaviour of the $\mathrm{Na}_{2} \mathrm{ZnP}_{2} \mathrm{O}_{7}$ compound have been studied as a function of temperature and frequency and an equivalent electrical circuit of the electrochemical cell has been proposed. The electrical transport is through $\mathrm{Na}^{+}$hopping mechanism. A comparison of the electrical properties in $\mathrm{Na}_{2} \mathrm{ZnP}_{2} \mathrm{O}_{7}$, $\mathrm{NaAgZnP} \mathrm{O}_{7}$ and $\mathrm{Ag}_{2} \mathrm{ZnP}_{2} \mathrm{O}_{7}$ compounds shows that the latter have the higher ionic conductivity and the lower activation energy.

\section{References}

Almond D P and West A R 1987 J. Solid State Ionics 2327 Anantha P S and Hariharan K 2005 J. Mater. Sci. \& Eng. B121 12 Ben Rhaiem A, Hlel F, Guidara K and Gargouri M 2009a $J$. Alloy. Compd. $\mathbf{4 8 5} 718$
Ben Rhaiem A, Chouaib S and Guidara K 2009b J. Ionics (accepted)

Ben Rhaiem A, Guidara K, Gargouri M and Daoud A 2005 J. Alloy. Compd. 87392

Belharouak I, Gravereau P, Parent C, Chaminade J P, Lebraud E and Le Flem G 2000 J. Solid State Chem. 152466

Chen S A and Liao C S 1993 J. Macromol. 262810

Dridi N, Boukhari A, Réau J M, Rbib E and Holt E M 2000 J. Solid State Ionics 127141

Dridi N, Boukhari A, Réau J M, Rbib E and Holt E M 2001 J. Mater. Letts. 47212

Erragh F, Boukhari A and Holt E M 1998 J. Acta Crystallogr. C54 1373

Erragh F, Boukhari A, Eloudi B and Abraham F 1995 J. Solid State Chem. 12023

El Maadi A, Boukhari A and Holt E M 1995 J. Chem. Crystal$\log r .25531$

Ganguli M, Harish Bhat M and Rao K J 1999 J. Phys. Chem. Glasses $\mathbf{4 0} 297$

Ghosh S and Ghosh A 2002 J. Solid State Ionics 14967

Gómez D and Algría A 2001 J. Non-Crystallogr. Solids 287 246

Hodge L M, Ingram M D and West A R 1976 J. Electroanal. Chem. 74125

Jarboui A, Ben Rhaiem A, Hlel F, Guidara K and Gargouri M 2010 J. Ionics 1667

Jonscher A K 1977 J. Nature (London) 267673

Kuhlmann U, Thomsen C, Prokoviev A V, Bullesfeld F, Uhrig E and Assmus W 2001 J. Physica B301 285

Lenfredi S, Saia P S, Lebullenger R and Hemandes A C 2002 J. Solid State Ionics 146329

Louati B, Gargouri M, Guidara K and Mhiri T 2005 J. Phys. Chem. Solids 66762

Mahadevan Pillai V P, Thomas B R, Nayar V and Lii K H 1999 J. Spectrochim. Acta A55 1809

Nadeem M, Akhtar M J and Khan A Y 2005 Sol. State Commun. 134431

Padmasree K P, Kanchan D K and Kulkarni A R 2006 J. Solid State Ionics 177475

Papathanassiou A N 2005 J. Chem. Solids 661849

Parathan D K, Samantry B K, Chauthaey R N P and Thakur A K 2005 J. Mater. Sci. Eng. B116 431

Reau J M, Jun X Y, Senegas J, Le Deit Ch and Poulain M 1997 J. Solid State Ionics 95191

Santha N, Nayar V and Keresztury G 1993 J. Spectrochim. Acta A49 47

Sanz F, Parada C, Rojo J M, Ruiz-Valero C and Saez-Puche R 1999 J. Solid State Chem. 145604

Sural M and Gosh A 2000 J. Solid State Ionics 130259

Uvarov N F, Hairetdinov E F, Reau J M, Bobe J M, Senegas J and Poulain M 1994 J. Solid State Ionics 74195 